Journal of Engineering and Applied Sciences 14 (Special Issue 8): 10369-10374, 2019

ISSN: $1816-949 \mathrm{X}$

(C) Medwell Journals, 2019

\title{
Synchronization of Hyperchaotic Rabinovich Systems Based on Adaptive Controller
}

\author{
Ehab A. Hussein and Murtadha K. Khashan \\ Department of Electrical Engineering, University of Babylon, Babylon, Iraq
}

\begin{abstract}
Security of information in communication field needs to high synchronization strategy between systems, this study deals with the issue of synchronization of acontinuous-type hyperchaotic systems based communications. Two way synchronization method which is adaptive synchronization is designed and implemented based on 4D Rabinovich systems using the theory of Lyapunov stability. An adaptive control laws are developed to stabilize the hyperchaotic Rabinovich system to the unstable fixed point at the origin. Then the adaptive parameters rules are derived to obtain the global chaotic synchronization of identical hyperchaos Rabinovich systems with unidentified parameters. Simulation results demonstrate to show the activity of the studied method.
\end{abstract}

Key words: Adaptive synchronization, Rabinovich system, 4D hyperchaos, Lyapunov theory, developed, studied method

\section{INTRODUCTION}

Since, systems based chaos are sensitively to initial conditions and system parameters, synchronization between systems must achieve when chaotic dynamical systems utilized in communication field. The synchronization method deals with two chaotic systems one of them is the master (transmitter system) and the other is the slave (receiver system) where the coupled systems are different in initial conditions ( $\mathrm{Xu}$ et al., 2009).

The principle thought of the synchronization makes two chaotic models which having an extremely touchy conduct to beginning conditions change having similar elements. The synchronization is considered as the real thought of the communication which is in light of the chaos, so, the security will be verified (Sorrentino et al., 2010; Banerjee et al., 2011). By the adaptive synchronization which is considered as one sort of the synchronization strategy, the general states of the drive system are sent by the communications channel and the slave is worked from similar differential equations (Zhang et al., 2006). Several works of adaptive synchronization were applied on the chaotic systems in $2016 \mathrm{X}$. Chen et al. (2016) introduced the synchronization of multiple chaotic systems with unknown parameters. In 2018, presented an adaptive synchronization and circuit implementation of a $4 \mathrm{D}$ hyperjerk system (Daltzis et al., 2018). The model practices which are created by Rabinovich framework are two types one of them is complicated and the other is easy where it is resolved regarding parameters values that are building the drive framework, so, they are equivalent dynamical frameworks yet the parameters of the slave don't known, so, these frameworks could be synchronized from inferring the laws of the control-adaptive, so, the present states for the two frameworks will be the equivalent and by the guide of the hypothesis of Lyapunov stability (Xiang-Jun, 2006).

In this study the adaptive synchronization kind is connected to Rabinovich model and as one use of the proposed hyperchaotic system, the complete communication systems are improved.

Rabinovich system: Hyperchaotic system is defined by four 1st order differential equations with the non-linearity conditions satisfied in the all equations (Tong et al., 2015) (Eq. 1):

$$
\begin{aligned}
& \dot{x}=h y-a x+y z \\
& \dot{y}=h x-b y-x z \\
& \dot{z}=-d z+x y+w^{2} \\
& \dot{w}=x y+c w
\end{aligned}
$$

The Rabinovich system performs different dynamics, for example: fixed point, periodic, a quasi-periodic and hyperchaotic. This system has nine fixed points can be estimated after equalizing hyperchaotic system (1) to zero (Eq. 2):

$$
\begin{aligned}
& \text { hy-ax }+y z=0 \\
& \text { hx-by-xz }=0 \\
& -d z+x y+w^{2}=0 \\
& x y+c w=0
\end{aligned}
$$

In equilibrium point, $\mathrm{P}_{0}(0,0,0,0)$ the Jacobi matrix is Eq. 3: 

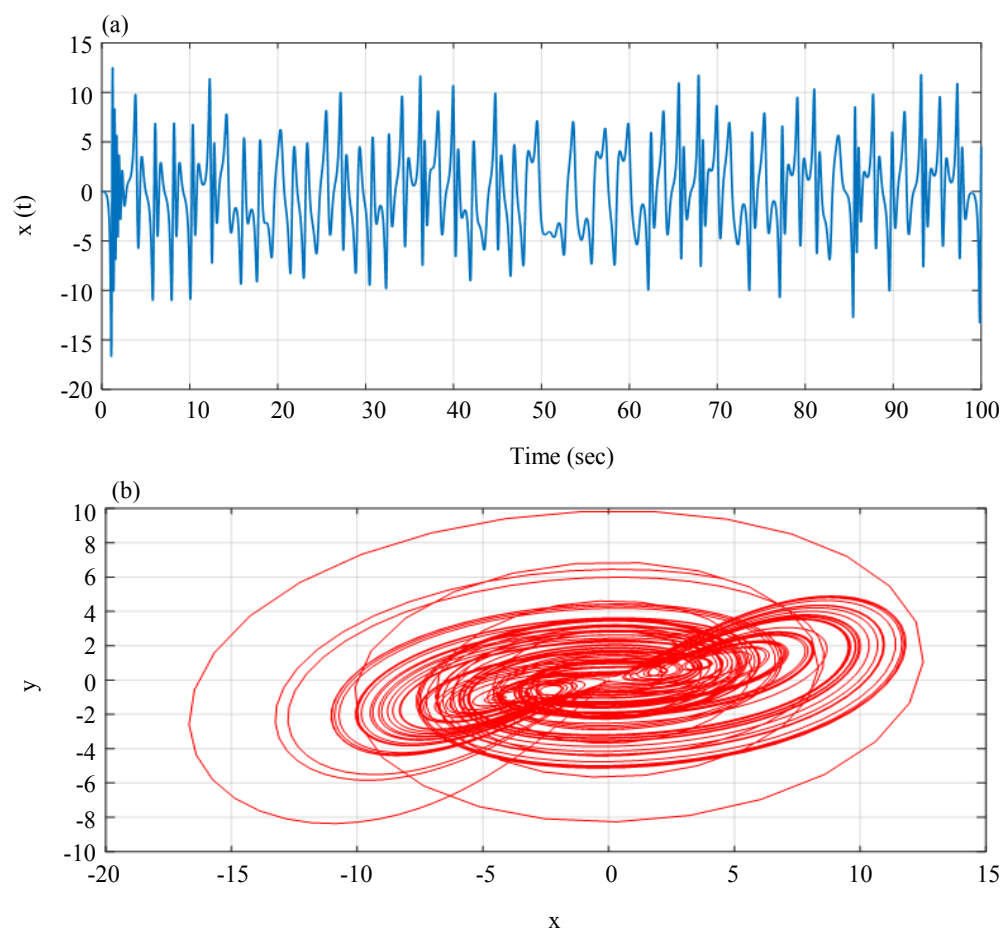

Fig. 1: (a) Time series waveform of $x$ and $b$ ) Phase portrait in terms of $x y$

$$
J_{o}=\left[\begin{array}{cccc}
-a & h & 0 & 0 \\
h & -b & 0 & 0 \\
0 & 0 & -d & 0 \\
0 & 0 & 0 & c
\end{array}\right]
$$

The eigenvalues of Jacobi matrix are: -10.1567 , $-2.2400,-1.0000$ and 6.6567. Since, there is one eigenvalue is positive, the equilibrium point is a saddle. Calculations show that the other remaining "eight equilibrium points", each one equilibrium point have at least one of the eigenvalues is $>0$. As a result, the equilibrium points of the model are all saddles.

The numerical simulation of Rabinovich Model executed using parameter values: $c=-2.24, b=-0.50$, $\mathrm{a}=4, \mathrm{~d}=1, \mathrm{~h}=8.10$ for the specified parameters, the time series $\mathrm{x}$ wave form and phase portrait (xy) are duplicated in Fig. 1.

\section{MATERIALS AND METHODS}

Synchronization based controller: The synchronization technique used in this study is the adaptive controller based the master-slave synchronization, both master and slave systems are considered as identical and both synchronized systems were built on hyperchaos Rabinovich system. The master system Eq. 4:

$$
\begin{aligned}
& \dot{\mathrm{X}}_{\mathrm{m}}=\mathrm{hy}_{\mathrm{m}}-\mathrm{a}_{1} \mathrm{x}_{\mathrm{m}}+\mathrm{y}_{\mathrm{m}} \mathrm{z}_{\mathrm{m}} \\
& \dot{\mathrm{y}}_{\mathrm{m}}=\mathrm{hx}_{\mathrm{m}}-\mathrm{by}_{\mathrm{m}}-\mathrm{x}_{\mathrm{m}} \mathrm{z}_{\mathrm{m}} \\
& \dot{\mathrm{z}}_{\mathrm{m}}=-\mathrm{a}_{2} \mathrm{z}_{\mathrm{mm}}+\mathrm{x}_{(\mathrm{m})} \mathrm{y}_{\mathrm{m}}+\mathrm{w}_{\mathrm{m}}^{2} \\
& \dot{\mathrm{w}}_{\mathrm{m}}=\mathrm{x}_{\mathrm{m}} \mathrm{y}_{\mathrm{m}}+\mathrm{a}_{3} \mathrm{w}_{\mathrm{m}}
\end{aligned}
$$

where, $\mathrm{m}$ and $\mathrm{s}$ subscript are the master and slave systems, respectively. The detailed Simulink implemented model of master system viewed in Fig. 2. The slave system Eq. 5:

$$
\begin{aligned}
& \dot{\mathrm{x}}_{\mathrm{s}}=\mathrm{hy}_{\mathrm{s}}-\mathrm{b}_{1} \mathrm{x}_{\mathrm{s}}+\mathrm{y}_{\mathrm{s}} \mathrm{z}_{\mathrm{s}}+\mathrm{u}_{1} \\
& \dot{\mathrm{y}}_{\mathrm{s}}=\mathrm{hx}_{\mathrm{s}}-\mathrm{by}_{\mathrm{s}}-\mathrm{x}_{\mathrm{s}} \mathrm{z}_{(\mathrm{s})}+\mathrm{u}_{2} \\
& \mathrm{z}_{\mathrm{s}}=-\mathrm{b}_{2} \mathrm{z}_{\mathrm{s}}+\mathrm{x}_{(\mathrm{s})} \mathrm{y}_{\mathrm{s}}+\mathrm{w}_{\mathrm{s}}^{2}+\mathrm{u}_{3} \\
& \dot{\mathrm{W}}_{\mathrm{s}}=\mathrm{x}_{\mathrm{s}} \mathrm{y}_{\mathrm{s}}+\mathrm{b}_{3} \mathrm{~W}_{\mathrm{s}}+\mathrm{u}_{4}
\end{aligned}
$$

where, $u_{i}(i=1,2,3,4)$ are the controller. The detailed Simulink implemented model of slave system viewed in Fig. 3. The synchronization errors between drive (transmitter) and response (receiver) systems are Eq. 6:

$$
\begin{aligned}
& \mathrm{e}_{1}=\mathrm{x}_{\mathrm{s}}-\mathrm{x}_{\mathrm{m}} \\
& \mathrm{e}_{2}=\mathrm{y}_{\mathrm{s}}-\mathrm{y}_{\mathrm{m}} \\
& \mathrm{e}_{3}=\mathrm{z}_{\mathrm{s}}-\mathrm{z}_{\mathrm{m}} \\
& \mathrm{e}_{4}=\mathrm{w}_{\mathrm{s}}-\mathrm{w}_{\mathrm{m}}
\end{aligned}
$$




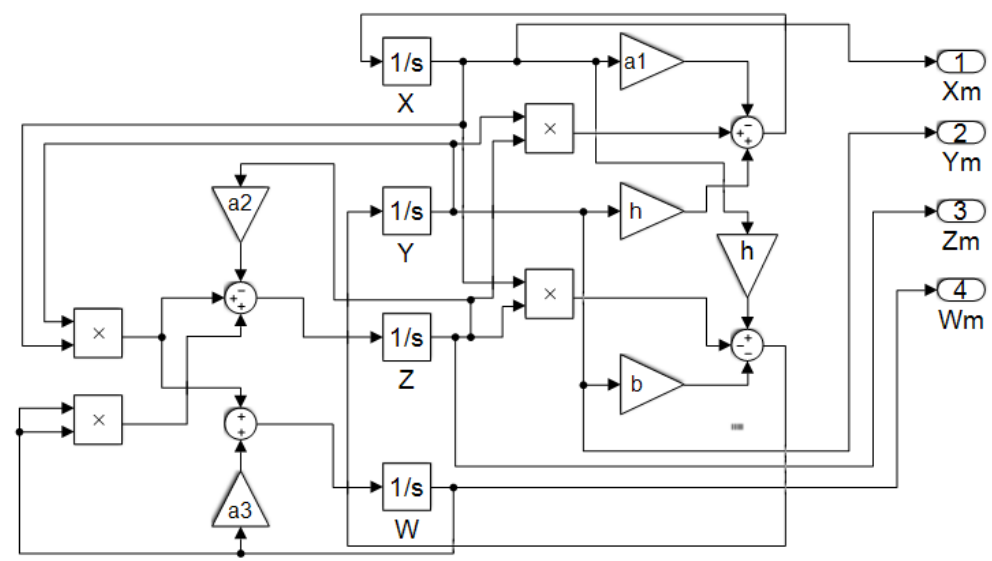

Fig. 2: Scheme of master system in Simulink model

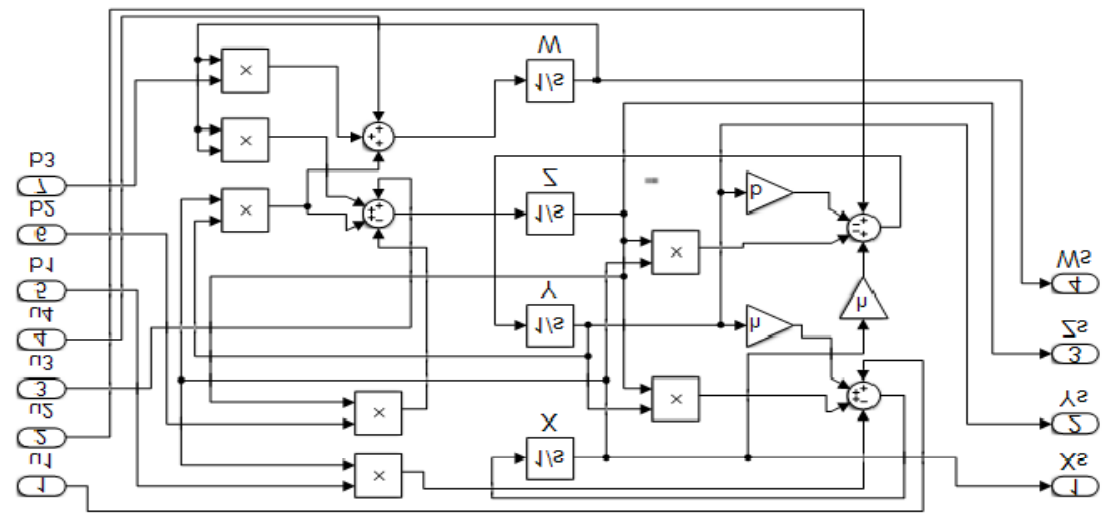

Fig. 3: Scheme of slave system in Simulink model

The dynamics of the error equations are found, according to Eq. 6 :

$$
\begin{gathered}
\dot{\mathrm{e}}_{1}=\dot{\mathrm{x}}_{\mathrm{s}}-\dot{\mathrm{x}}_{\mathrm{m}} \dot{\mathrm{e}}_{1}=h \mathrm{e}_{2}-\mathrm{b}_{1}(\mathrm{t}) \mathrm{e}_{1}-\left(\mathrm{b}_{1(\mathrm{t})}-\mathrm{a}_{1}\right) \\
\mathrm{x}_{\mathrm{m}}+\mathrm{e}_{2} \mathrm{e}_{3}+\mathrm{z}_{\mathrm{m}} \mathrm{e}_{2}+\mathrm{e}_{3} \mathrm{y}_{\mathrm{m}}+\mathrm{u}_{1} \\
\dot{\mathrm{e}}_{2}=\dot{\mathrm{y}}_{\mathrm{s}}-\dot{\mathrm{y}}_{\mathrm{m}} \dot{\mathrm{e}}_{2}=h \mathrm{e}_{1}-\mathrm{be}_{2}-\mathrm{e}_{1} \mathrm{e}_{3}-\mathrm{e}_{1} \mathrm{z}_{\mathrm{m}}-\mathrm{e}_{3} \mathrm{x}_{\mathrm{m}}+\mathrm{u}_{2} \\
\dot{\mathrm{e}}_{3}=\dot{\mathrm{z}}_{\mathrm{s}}-\dot{\mathrm{z}}_{\mathrm{m}} \dot{\mathrm{e}}_{3}=-\mathrm{b}_{2}(\mathrm{t}) \mathrm{e}_{3}-\mathrm{z}_{\mathrm{m}}\left(\mathrm{b}_{2}(\mathrm{t})-\mathrm{a}_{2}\right)+ \\
\mathrm{e}_{1} \mathrm{e}_{2}+\mathrm{e}_{1} \mathrm{y}_{\mathrm{m}}+\mathrm{e}_{2} \mathrm{x}_{\mathrm{m}}+\mathrm{e}_{4}^{2}+2 \mathrm{w}_{\mathrm{m}} \mathrm{e}_{4}+\mathrm{u}_{3} \\
\dot{\mathrm{e}}_{4}=\dot{\mathrm{w}}_{\mathrm{s}}-\dot{\mathrm{w}}_{\mathrm{m}} \dot{\mathrm{e}}_{4}=\mathrm{e}_{1} \mathrm{e}_{2}+\mathrm{e}_{1} \mathrm{y}_{\mathrm{m}}+\mathrm{e}_{2} \mathrm{x}_{\mathrm{m}}+ \\
\mathrm{b}_{3}(\mathrm{t}) \mathrm{e}_{4}+\mathrm{w}_{\mathrm{m}}\left(\mathrm{b}_{3}(\mathrm{t})-\mathrm{a}_{3}\right)+\mathrm{u}_{4}
\end{gathered}
$$

The equations of the controller can be gained from the Lyapunov stability theory condition, the selection Lyapunov function is defined as:

$$
\begin{aligned}
& V(t)=V\left(e_{1}, e_{2}, e_{3}, e_{4}, e_{b 1}, e_{b 2}, e_{b 3}\right) \\
& V(t)=\frac{1}{2}\left(e_{1}^{2}+e_{2}^{2}+e_{3}^{2}+e_{4}^{2}+e_{d}^{2}\right)
\end{aligned}
$$

where " $e_{d}$ " is the error variation between the drive and response parameters values Eq. 12:

$$
e_{d}=b(t)-a
$$

With respect to Lyapunov function condition the dynamical error converges to zero:

$$
\begin{aligned}
& \dot{v}(t)=e_{1} \dot{e}_{1}+e_{2} \dot{e}_{2}+e_{3} \dot{e}_{3}+e_{4} \dot{e}_{4}+e_{b 1} \dot{e}_{b 1}+e_{b 2} \dot{e}_{b 2}+e_{b 3} \dot{e}_{b 3} \\
& \dot{v}(t)=\left[h e_{2}-b_{1}(t) e_{1}-\left(b_{1}(t)-a_{1}\right) x_{m}+e_{2} e_{3}+z_{m} e_{2}+e_{3} y_{m}+u_{1}\right] e_{1}+ \\
& {\left[h e_{1}-b_{2}-e_{1} e_{3}-e_{1} z_{m}-e_{3} x_{m}+u_{2}\right] e_{2}+} \\
& {\left[-b_{2}(t) e_{3}-z_{m}\left(b_{2}(t)-a_{2}\right)+e_{1} e_{2}+e_{1} y_{m}+e_{2} x_{m}+e_{4}^{2}+2 w_{m} e_{4}+u_{3}\right] e_{3}+} \\
& {\left[e_{1} e_{2}+e_{1} y_{m}+e_{2} x_{m}+b_{3}(t) e_{4}+w_{m}\left(b_{3}(t)-a_{3}\right)+u_{4}\right] e_{4}+} \\
& \left(-a_{1}+b_{1}(t)\right) \dot{b}_{1}(t)+\left(-a_{2}+b_{2}(t)\right) \dot{b}_{2}(t)+\left(-a_{3}+b_{3}(t)\right) \dot{b}_{3}(t)
\end{aligned}
$$


The aim is to show the reasonableness controller model and updating rules to the response parameter estimation when the model 4 will be made synchronization together with the slave system of Eq. 5 . Then, the controller is suggested as Eq. 14:

$$
\begin{aligned}
& \mathrm{u}_{1}(t)=-h e_{2}+\mathrm{b}_{1} \mathrm{e}_{1}-\mathrm{e}_{2} \mathrm{e}_{3}-\mathrm{e}_{2} \mathrm{z}_{\mathrm{m}}-\mathrm{e}_{3} \mathrm{y}_{\mathrm{m}}-\mathrm{e}_{1} \\
& \mathrm{u}_{2}(\mathrm{t})=-h \mathrm{e}_{1}+\mathrm{be}_{2}+\mathrm{e}_{1} \mathrm{e}_{3}+\mathrm{e}_{1} \mathrm{z}_{\mathrm{m}}+\mathrm{e}_{3} \mathrm{x}_{\mathrm{m}}-\mathrm{e}_{2} \\
& \mathrm{u}_{3}(\mathrm{t})=\mathrm{b}_{2} \mathrm{e}_{3}-\mathrm{e}_{1} \mathrm{e}_{2}-\mathrm{e}_{1} \mathrm{y}_{\mathrm{m}}-\mathrm{e}_{2} \mathrm{x}_{\mathrm{m}}-\mathrm{e}_{4}^{2}-2 \mathrm{w}_{\mathrm{m}} \mathrm{e}_{4}-\mathrm{e}_{3} \\
& \mathrm{u}_{4}(\mathrm{t})=-\mathrm{e}_{1} \mathrm{e}_{2}-\mathrm{e}_{1} \mathrm{y}_{\mathrm{m}}-\mathrm{e}_{2} \mathrm{x}_{\mathrm{m}}-\mathrm{b}_{3} \mathrm{e}_{4}-\mathrm{e}_{4}
\end{aligned}
$$

The parameter estimation is impossible by the coupling of direct synchronization; therefore, the proposed adaptive controller method will solve these issues. So, the updating laws of slave parameter estimation are given by:

$$
\begin{aligned}
& \dot{\mathrm{b}}_{1}(\mathrm{t})=\mathrm{x}_{\mathrm{m}} \mathrm{e}_{1} \\
& \dot{\mathrm{b}}_{2}(\mathrm{t})=\mathrm{z}_{\mathrm{m}} \mathrm{e}_{3} \\
& \dot{\mathrm{b}}_{3}(\mathrm{t})=-\mathrm{w}_{\mathrm{m}} \mathrm{e}_{4}
\end{aligned}
$$

\section{RESULTS AND DISCUSSION}

The simulation results of the system can be approved the performance of this method. The parameters of the drive hyperchaotic system are chosen as $h=8.1, a_{1}=4$, $\mathrm{b}=-0.5, \mathrm{a}_{2}=1, \mathrm{a}_{3}=-2.24$. The initial conditions of drive model 4 and slave (receiver) model 5 have been choosed to $\mathrm{x}_{\mathrm{m}}(0)=0.09, \mathrm{y}_{\mathrm{m}}(0)=-0.09, \mathrm{z}_{\mathrm{m}}(0)=-0.1, \mathrm{w}_{\mathrm{m}}(0)$ $=-0.1$ and $x_{s}(0)=1.01, y_{s}(0)=1.03, z_{s}(0)=2, w_{s}(0)$ $=-0.3$, respectively. The beginning values of the calculated parameters are supposed as $b_{1}(0)=0.3$, $\mathrm{b}_{2}(0)=0.1, \mathrm{~b}_{3}(0)=1$, the time response results are clarified in Fig. 4 while the errors of synchronization (Fig. 5). The calculated parameters and converge to the drive parameter values: $b_{1}=4, b_{2}=1$ and $b_{3}=-2.24$ as clarified in Fig. 6 . The phase portrayal between the master states $x_{m}(t), y_{m}(t)$ and slave states $\mathrm{x}_{\mathrm{s}}(\mathrm{t}), \mathrm{y}_{\mathrm{s}}(\mathrm{t})$ are viewed in Fig. 7. The hardness of the proposed technique will be confirmed in the realized results.

The simulation results of the proposed adaptive synchronization method can be proved the performance of this technique. From Fig. 4 and 5 results, we notice that two systems (master and slave) completely synchronized after a certain time for instance the synchronization between $x_{m}$ and $x_{s}$ states is completed at error nearly to $12 \mathrm{sec}$ while the synchronization error between $\mathrm{y}_{\mathrm{m}}$ and $\mathrm{y}_{\mathrm{s}}$ states we need nearly to $2.3 \mathrm{sec}$. The whole synchronization error between systems is completed after nearly a $15 \mathrm{sec}$.
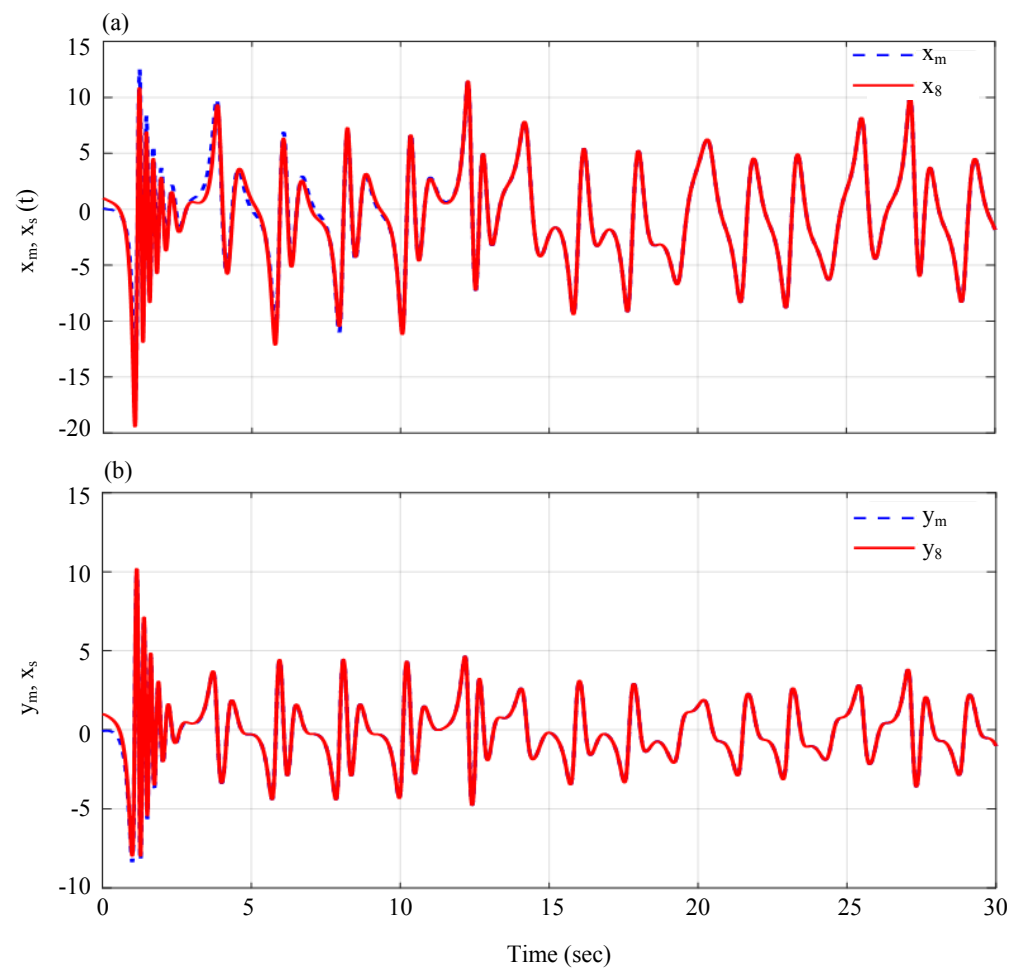

Fig. 4: Systems synchronization by the controller as in Eq. 14. The state series of master (dashed line) and the conforming slave (solid line) show whole synchronization: (a) $\mathrm{x}_{\mathrm{m}}, \mathrm{x}_{\mathrm{s}}(\mathrm{t})$ and (b) $\mathrm{y}_{\mathrm{m}}, \mathrm{y}_{\mathrm{s}}(\mathrm{t})$ 


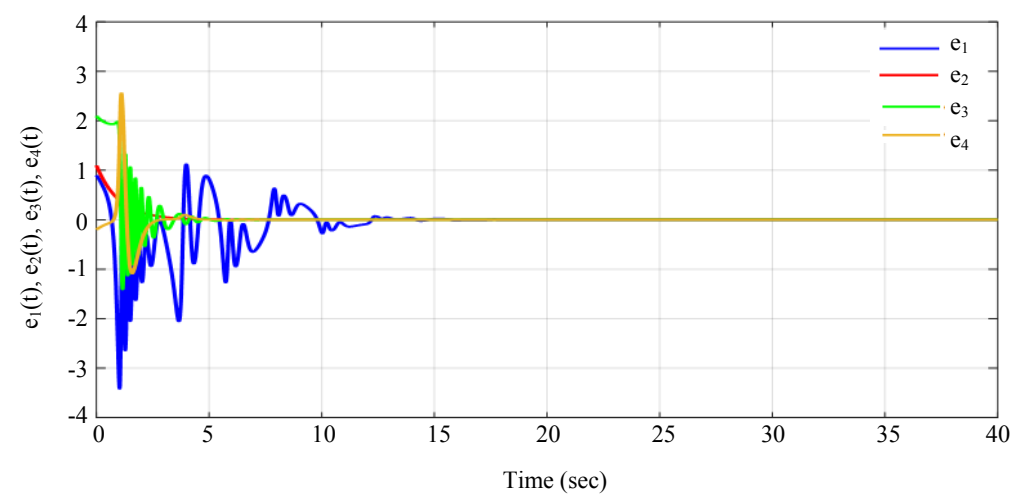

Fig. 5: The error of synchronization. The errors approach to zeros when the controller is activated at around $\mathrm{t}=15 \mathrm{sec}$

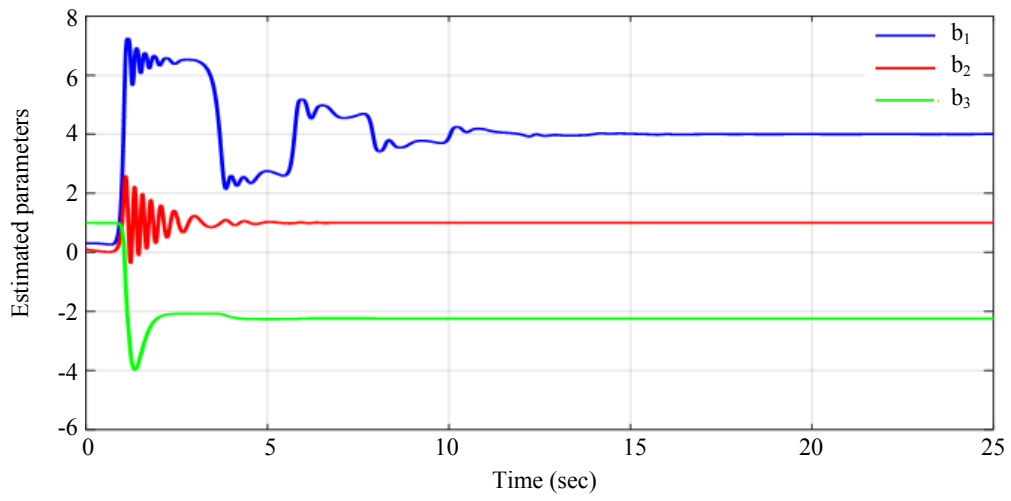

Fig. 6: Time series response of $b_{1}, b_{2}$ and $b_{3}$
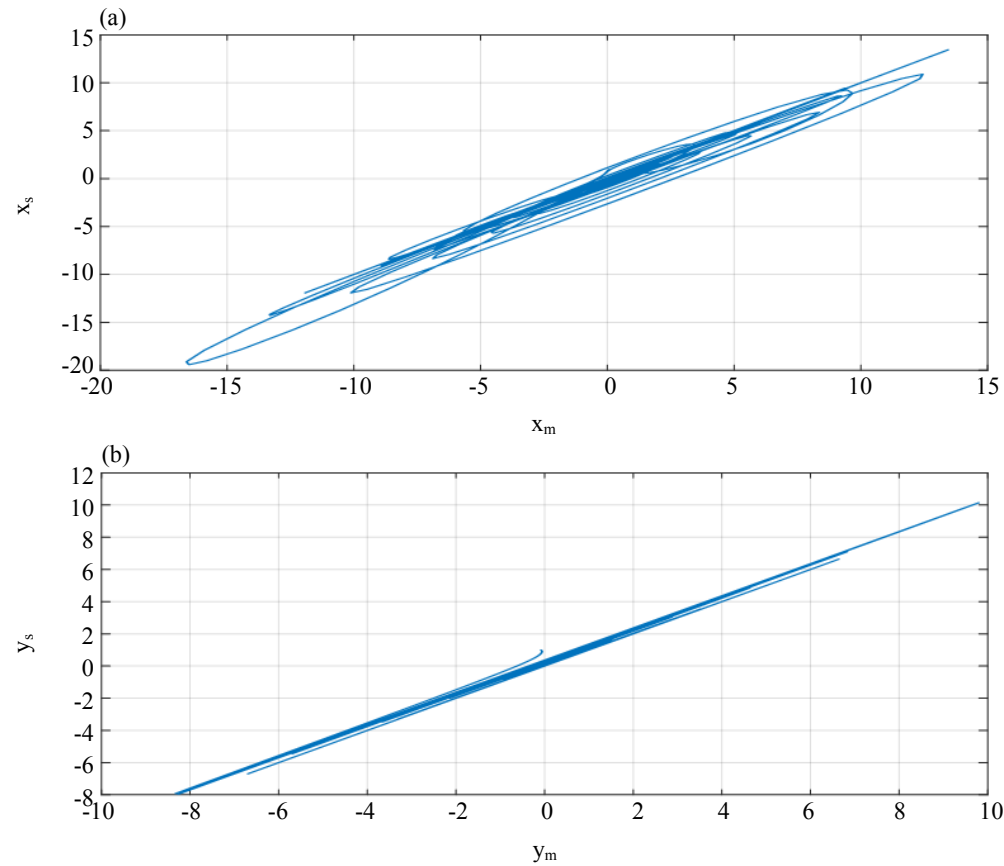

Fig. 7: The phase portrait describes: (a) The $x_{m}(t)$ versus $x s(t)$ and (b) The $y_{m}(t)$ versus $y_{s}(t)$ 
Figure 6 satisfy the adaptive parameters laws as in Eq. 15 which estimate the unknown parameters at slave system, for example, the value of $a_{3}$ parameter in this simulation is set to -2.24 which is at master system in Fig. 6 the green line represent the value of the parameter $b_{3}$ from the slave side which is opposite to the $\mathrm{a}_{3}$ parameter at master system which is calculated when the activation of the controller after about a $4 \mathrm{sec}$ time.

\section{CONCLUSION}

In this research, we used adaptive theory for the synchronization and stabilization of the hyperchaotic Rabinovich Model with unknown parameters in the slave system. Firstly adaptive control laws were designed to stabilize the hyperchaos Rabinovich system to its equilibrium origin point established on the adaptive controller theory and stability of Lyapunov theory. Later we investigated adaptive synchronization strategy and updating laws for system parameter estimation. Master/slave systems are executed with different initial conditions and parameters. The oretical results are shown to confirm the performance of the suggested adaptive synchronization scheme.

\section{REFERENCES}

Banerjee, S., M. Mitra and L. Rondoni, 2011. Applications of Chaos and Nonlinear Dynamics in Engineering. Vol. 1, Springer, Berlin, Germany, ISBN: 978-3-642-21922-1, Pages: 346.
Chen, X., J. Cao, J. Qiu, A. Alsaedi and F.E. Alsaadi, 2016. Adaptive control of multiple chaotic systems with unknown parameters in two different synchronization modes. Adv. Difference Equations, Vol. 2016, No. 1. 10.1186/s13662-016-0959-3

Daltzis, P.A., C.K. Volos, H.E. Nistazakis, A.D. Tsigopoulos and G.S. Tombras,a 2018. Analysis, synchronization and circuit design of a 4D hyperchaotic hyperjerk system. Comput., Vol. 6, No. 1. $10.3390 /$ computation 6010014

Sorrentino, F., G. Barlev, A.B. Cohen and E. Ott, 2010. The stability of adaptive synchronization of chaotic systems. Chaos Interdiscip. J. Nonlinear Sci., Vol. 20, No. 1. 10.1063/1.3279646

Tong, X., Y. Liu, M. Zhang, H. Xu and Z. Wang, 2015. An image encryption scheme based on hyperchaotic Rabinovich and exponential chaos maps. Entropy, 17: 181-196.

Xiang-Jun, W., 2006. A new chaotic communication scheme based on adaptive synchronization. Chaos Interdiscip. J. Nonlinear Sci., Vol. 16, No. 4. $10.1063 / 1.2401058$

$\mathrm{Xu}$, J., G. Cai and S. Zheng, 2009. Adaptive synchronization for an uncertain new hyperchaotic Lorenz system. Int. J. Nonlinear Sci., 8: 117-123.

Zhang, H., W. Huang, Z. Wang and T. Chai, 2006. Adaptive synchronization between two different chaotic systems with unknown parameters. Phys. Lett. A., 350: 363-366. 